\title{
TESTE DE CONSTRIÇÃO ABDOMINAL NÃO APRESENTA EFEITO SOBRE O COMPORTAMENTO EXPLORATÓRIO DE CAMUNDONGOS ALBINOS (Mus musculus) NO LABIRINTO EM CRUZ ELEVADO
}

Claudio Herbert Nina-e-Silva, Laboratório de Psicologia Anomalística e Neurociências, Universidade de Rio Verde, claudio_herbert@yahoo.com.br.

Lenny Francis Campos de Alvarenga, Laboratório de Psicologia Anomalística e Neurociências, Universidade de Rio Verde.

Eliane Andréia dos Santos Oliveira, Curso de Ciências Biológicas, Instituto Federal Goiano, Campus de Rio Verde.

\section{Recebido em: 07/04/2014 - Aprovado em: 30/06/2014 - Disponibilizado em: 30/07/2014}

Resumo: Apesar da realização de vários trabalhos sobre os efeitos antinoceptivos do confinamento de camundongos nos braços abertos do labirinto em cruz elevado (LCE), poucos estudos investigaram o efeito da estimulação nociceptiva sobre o comportamento exploratório propriamente dito. Além, não há consenso na literatura acerca da influência da estimulação nociceptiva sobre o comportamento exploratório do camundongo no LCE. Portanto, o objetivo deste trabalho foi investigar o efeito do teste de constrição abdominal sobre o comportamento exploratório de camundongos albinos no LCE. Camundongos albinos (Mus musculus) adultos foram distribuídos em dois grupos: ACA (n=05) e SAL $(\mathrm{n}=05)$. No grupo ACA, os animais foram tratados com $0,05 \mathrm{ml} / \mathrm{kg}$ de ácido acético 0,6\% i.p. No grupo SAL, os animais receberam injeção i.p. de salina. Uma hora depois, os animais foram expostos, individualmente, ao LCE por cinco minutos. Registrou-se o tempo de permanência nos braços abertos do LCE. Não foi observada diferença estatisticamente significativa $(t=-0,21999, p<0,001)$ na duração média dos tempos de permanência nos compartimentos do LCE entre os animais dos dois grupos. . Devido à influência ativadora da dor sobre a resposta fisiológica ao estresse, esperava-se que os sujeitos do grupo ACA permanecessem menos tempo nos braços abertos do LCE do que os do grupo SAL. Os presentes resultados indicaram que a dor resultante do teste de constrição abdominal parece não influenciar no comportamento exploratório de camundongos no LCE.

Palavras-chave: Comportamento exploratório; dor; ansiedade; camundongo; psicofarmacologia; labirinto em cruz elevado.

\begin{abstract}
Several studies have investigated the antinoceptive effects of confinement of mice in the open arms of the elevated plus maze (EPM). Nevertheless, there have been few studies attempting to investigate the effect of nociceptive stimulation on exploratory behavior itself. In addition, there is no consensus in the literature about the influence of nociceptive stimulation on exploratory behavior of mice in the EPM. Therefore, the aim of this work was to verify the effect of abdominal constriction test on the exploratory behavior of albino mice in the EPM. Adult Albino mice (Mus musculus) were divided into two groups: ACA $(\mathrm{n}=05)$ and SAL $(\mathrm{n}=05)$. In the ACA group, the animals were treated with $0.05 \mathrm{ml} / \mathrm{kg}$ of $0.6 \%$ acetic acid (intraperitoneal). In the SAL group, the animals received intraperitoneal injection of saline. One hour later, the animals were exposed individually to the EPM for five minutes. The time spent in the open arms of the EPM was recorded. There was no statistically significant difference $(t=-0.21999, p<0.001)$ in the average duration of residence times in compartments LCE between animals of the two groups. Due to the activating influence of pain on the physiological response to stress, it was expected that the subjects of the ACA group remain less time in the open arms of the EPM than the SAL group. The present results indicated that the pain resulting from abdominal constriction test does not influence the exploratory behavior of mice in the EPM.
\end{abstract}

Keywords: exploratory behavior; pain; anxiety; mice; psychopharmacology; elevated plus-maze.

\section{Introdução}

A exposição de camundongos (Mus musculus) ao labirinto em cruz elevado (LCE) é considerada um modelo animal experimental confiável e fidedigno para a investigação de agentes ansiolíticos e ansiogênicos (LISTER, 1987; HOGG, 1996;
BOURIN; $\quad$ PETIT-DEMOLIÈRE;

DHONNCHADHA; HASCÖET, 2007).

Por conta disso, o modelo do LCE é largamente empregado na pesquisa neuropsicofarmacológica da ansiedade (CAROBREZ; BERTOGLIO, 2005). Assim, tem-se considerado relevante a investigação de variáveis que possam vir a interferir na 
acurácia do LCE na avaliação da ansiedade em roedores (ITOH; NABESHIMA; KAMEYAMA, $\quad 1990 ; \quad$ PAWLAK; KARRENBAUER; SCHNEIDER; HO, 2012).

Um dos modelos mais frequentemente utilizados para a investigação da relação entre dor e ansiedade é o teste de constrição abdominal utilizando camundongos como sujeitos experimentais (LANGFORD; MOGIL, 2008; ZHONG; WEI; ZHOU; LUO; WANG; DUAN; BI; ZHANG; LI; DAI; LI, 2012). O teste consiste na contagem do número de contrações abdominais após administração intraperitoneal de agente químico irritante, frequentemente o ácido acético, no roedor (LANGFORD; MOGIL, 2008).

Embora Langford e Mogil (2008) salientem que a intensidade e a duração da dor visceral provocada pelo ácido acético no animal seja eticamente aceitável, Gawade (2012) considera os efeitos do teste de constrição abdominal intensamente dolorosos e demorados, recomendando que ele seja banido da experimentação animal (GAWADE, 2012).

A investigação da relação entre a dor e o comportamento exploratório de roedores no LCE tem se concentrado na avaliação do efeito antinociceptivo produzido pela ansiedade resultante da confinação dos sujeitos experimentais nos braços abertos do LCE (HOLMES; PARMIGIANI; FERRARIC; PALANZA; RODGERS, 2000;
NUNES-DE-SOUZA; CANTO-DE-SOUZA; DA-COSTA; FORNARI; GRAEFF; PELÁ, 2000; CANTO-DE-SOUZA; NUNES-DESOUZA; RODGERS, 2002; CRUZMORALES; SANTOS; BRANDÃO, 2002; GOMES; GARCIA; PLANETA; NUNESDE-SOUZA, 2005; SILVA; SORREGOTTI; EBINA; NUNES-DE-SOUZA, 2009; PAWLAK et al., 2012).

Contudo, poucos estudos investigaram a influência da dor sobre o comportamento exploratório no LCE propriamente dito (CATANI; ALVARENGA; SOUZA; VASCONCELOS-SILVA; NINA-E-SILVA, 2002; OLIVEIRA; MORAES; NINA-ESILVA, 2011; OLIVEIRA; NINA-E-SILVA; ALVARENGA, 2013).

Entretanto, os resultados desses estudos não são consensuais. Enquanto Catani et al. (2002) não observaram diferença significativa na freqüência e na duração do comportamento exploratório no LCE entre animais submetidos à estimulação dolorosa e o grupo controle, outros trabalhos mais recentes relataram o aumento da freqüência e da duração do comportamento exploratório de roedores no LCE após a estimulação dolorosa (OLIVEIRA; MORAES; NINA-E-SILVA, 2011; OLIVEIRA; NINA-E-SILVA; ALVARENGA, 2013).

Portanto, o presente estudo objetivou investigar o efeito do teste de constrição abdominal sobre o comportamento exploratório de camundongos albinos no LCE. 


\section{Materiais e Métodos}

Os animais experimentais foram $10 \mathrm{Mus}$ musculus albinos, machos, com idade de 2 meses e pesando entre 20 e 27 gramas. Os animais foram equitativamente distribuídos em dois grupos: teste de constrição abdominal (TCA, $n=5$ ) e salina (SAL, $\mathrm{n}=5$ ). No grupo ACA, os animais foram tratados com 0,05 $\mathrm{ml} / \mathrm{kg}$ de ácido acético 0,6\% i.p. No grupo SAL, os animais receberam injeção i.p. de salina.

Uma hora depois da administração de ácido acético ou de salina, os sujeitos foram expostos, individualmente, ao LCE (elevação de $40 \mathrm{~cm}$ do solo, paredes dos braços fechados de $50 \mathrm{~cm}$ e moldura acrílica dos braços abertos de 1 com de altura) por cinco minutos.

Registrou-se, para cada um dos animais experimentais, o tempo de permanência, em segundos, nos braços abertos do LCE.

\section{Resultados e Discussão}

Não houve diferença estatisticamente significativa $\quad(t=-0,21999, \quad p<0,001) \quad$ na duração média dos tempos de permanência nos braços abertos do LCE entre os animais dos dois grupos. (Figura 1). Os tempos médios de permanência nos braços abertos do LCE para os grupos ACA e SAL foram, respectivamente, $34,2 \mathrm{~s}$ e $35,6 \mathrm{~s}$.

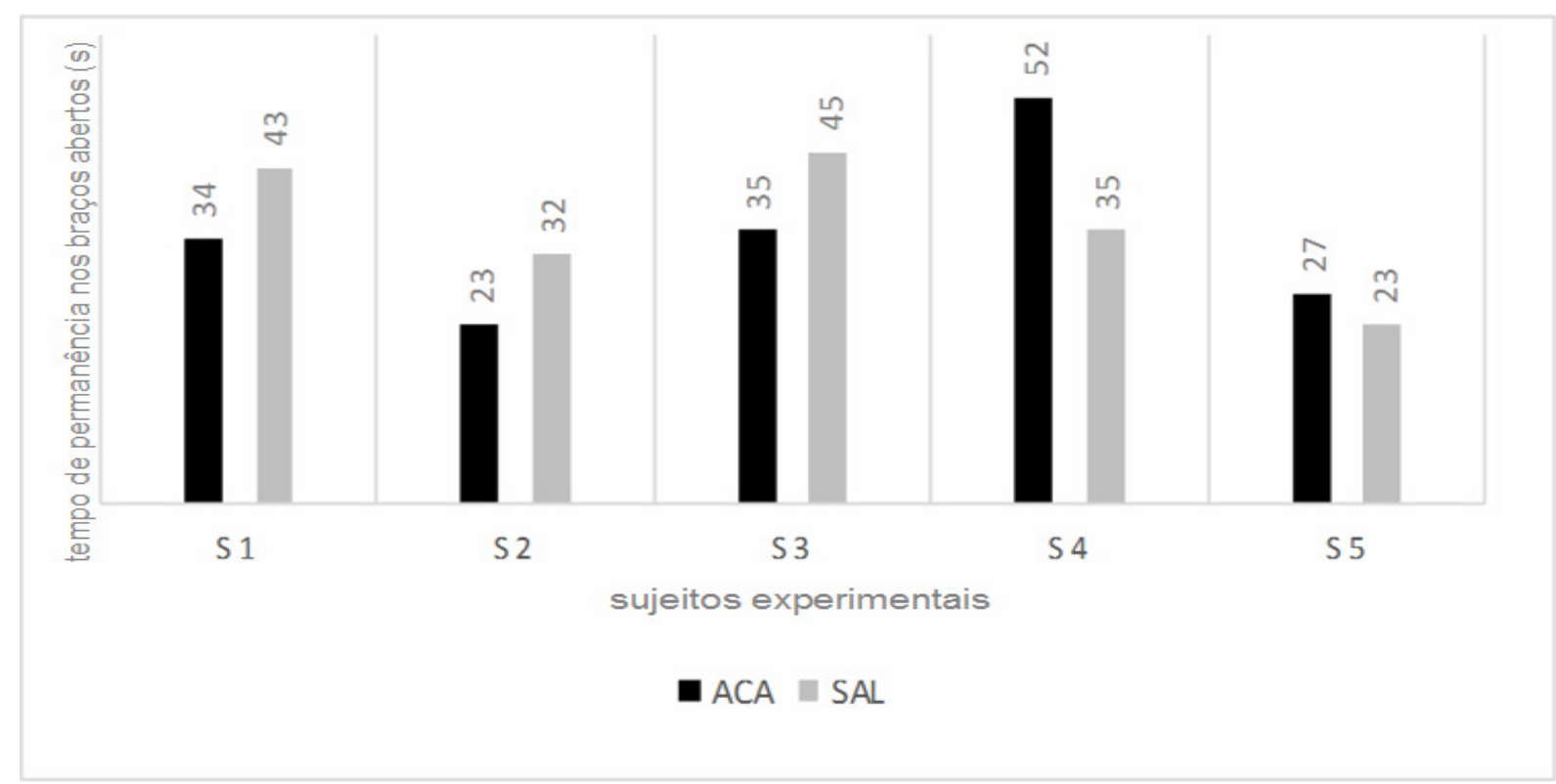

Figura 1. Tempo de permanência individual dos sujeitos experimentais nos braços abertos para os grupos ACA (ácido acético) e SAL (salina) em segundos. dolorosa não apresentaram diferenças

Esses resultados corroboraram achados prévios de Catani et al. (2002), Gomes et al. (2005) e Silva et al. (2009) segundos os quais camundongos expostos à estimulação significativas no comportamento exploratório em relação a animais não submetidos a estímulos nociceptivos. 
O fato de os animais de ambos os grupos terem apresentado praticamente os mesmos tempos médios de permanência nos braços abertos significa que os sujeitos do grupo ACA demonstraram a aversão natural dos camundongos a espaços abertos (LISTER, 1987; HOGG, 1996; CAROBREZ; BERTOGLIO, 2005; BOURIN et al., 2007).

Desse modo, a estimulação nociceptiva parece não ter interferido na expressão normal do padrão comportamental de defesa do camundongo contra predação que consiste na preferência pelos braços fechados do LCE e na evitação dos espaços abertos do aparato.

Esse achado pode ser explicado pelo fato de a ansiedade ocorrer em conjunto com a dor visceral induzida pela administração de ácido acético durante o teste de constrição abdominal (ZHONG et al., 2012).

A resposta imunológica a um agente nociceptivo que produz inflamação ativa a resposta neuroendócrina ao estresse, acarretando a ativação do eixo hipotálamohipofisário e a subsequente ocorrência dos sinais autonômicos relacionados à ansiedade (STOCCHE; GARCIA; KLAMT; 2001). Berkenkopf e Weichman (1988) já haviam demonstrado que, além de se relacionar diretamente com o mecanismo de dor inflamatória, a liberação de prostaglandinas resultante da administração intraperitoneal de ácido acético em um camundongo leva à ativação de receptores para glicocorticóides da amígala. Isso levaria à ocorrência de resposta fisiológica ao estresse e aos sinais comportamentais de ansiedade no roedor, incluindo a evitação de espaços abertos no LCE.

Devido à influência ativadora da dor sobre a resposta fisiológica ao estresse, esperava-se que os sujeitos do grupo ACA permanecessem menos tempo nos braços abertos do LCE do que os do grupo SAL. O fato de isso não ter acontecido requer novos estudos que possam esclarecer essa questão.

\section{Conclusão}

Embora haja evidência empírica do efeito antinociceptivo da ansiedade induzida pela exposição aos braços abertos do LCE, os presentes resultados indicaram que a dor resultante do teste de constrição abdominal parece não influenciar no comportamento exploratório de camundongos no LCE.

\section{Referências Bibliográficas}

BERKENKOPF, J.W.; WEICHMAN, B.M. Production of prostacyclin in mice following intraperitoneal injection of acetic acid, phenylbenzoquinone and zymosan: its role in the writhing response. Prostaglandins, 36, p.693-709, 1988

BOURIN, M.; PETIT-DEMOULIÈRE, B.; DHONNCHADHA, B.N.; HASCÖET. M. Animal models of anxiety in mice Fundamental and Clinical Pharmacology, 21, p. 567-574, 2007.

CANTO-DE-SOUZA, A.; NUNES-DESOUZA, R. L.; RODGERS, R. J. Anxiolyticlike effect of way-100635 microinfusions into the median (but not dorsal) raphe nucleus in mice exposed to the plus-maze: Influence of 
prior test experience. Brain Research, 928(12), p.50-59, 2002.

CAROBREZ, A.P.; BERTOGLIO, L.J. Ethological and temporal analyses of anxietylike behavior: The elevated plus-maze model 20 years on. Neuroscience \& Biobehavioral Reviews, 29(8), p.1193-1205, 2005.

CATANI, R.; ALVARENGA, L.F.C.; SOUZA, B.J.; VASCONCELOS-SILVA, A.; NINA-E-SILVA, C.H. Insensibilidade do labirinto em cruz elevada na detecção de ansiedade associada à indução de dor pelo ácido acético em camundongos albinos. Caderno de Resumos da 54 ${ }^{\mathrm{a}}$ Reunião Anual da Sociedade Brasileira para o Progresso da Ciência. Goiânia-Go, 2002.

CRUZ-MORALES, S. E., SANTOS, N. R., \& BRANDÃO, M. L. One-trial tolerance to midazolam is due to enhancement of fear and reduction of anxiolytic-sensitive behaviors in the elevated plus-maze retest in the rat. Pharmacology, Biochemistry and Behavior, 72, p.973-978, 2002.

GAWADE, J. Acetic acid induced painful endogenous infliction in writhing test on mice. Journal of Pharmacology and Pharmacotherapy, 3(4), p.348-351, 2012.

GOMES, K.S.; GARCIA, C.A.; PLANETA, C.S.; NUNES-DE-SOUZA, R.L. Fos-like immunoreactivity in central nervous system of mice simultaneously exposed to the elevated plus-maze and nociception. Revista Brasileira de Ciências Farmacêuticas, 41(3), p. 385-391, 2005.

HOGG, S. A review of the validity and variability of the Elevated Plus-Maze as an animal model of anxiety. Pharmacology, Biochemistry and Behavior, 54(1), p.21-30, 1996.

HOLMES,A.; PARMIGIANI, S.; FERRARI, P.F.; P. PALANZA, P.; RODGERS, R.J. Behavioral profile of wild mice in the elevated plus-maze test for anxiety. Physiology and Behavior, 71, p.509-516, 2000.
ITO, J.; TOSHITAKA; N.; TSUTOMU, K. Utility of an elevated plus-maze for the evaluation of memory in mice: effects of nootropics, scopolamine and electroconvulsive shock. Psychopharmacology, 101 (1), p.27-33, 1990.

LANGFORD, D.J.; MOGIL, J.S. Pain testing in the laboratory mouse. In: FISH, R.E.; BROWN, M.J.; DANNENAM, P.J.; KARAS, A.Z. (Org.). Anesthesia and analgesia in laboratory animals. San Diego: Elsevier, 2008, p.549-557.

LISTER, R.G. The use of a plus-maze to measure anxiety in the mouse. Psychopharmacology, 92, p.180-185, 1987.

NUNES-DE-SOUZA， R.L.; CANTO-DESOUZA, A.; DA-COSTA, M.; FORNARI, R.V.;GRAEFF, F.G.; PELÁ, I.R. Anxietyinduced antinociception in mice: effects of systemic and intra-amygdala administration of 8-OH-DPAT and midazolam. Psychopharmacology, 150(3), p.300-310, 2000.

OLIVEIRA, E.A.S.; MORAIS, L.P.; NINAE-SILVA, C.H. Efeito da indução de dor na expressão de ansiedade por camundongos albinos (Mus musculus) expostos ao labirinto em cruz elevado. Caderno de Resumos da $6^{a}$ Reunião Anual da Sociedade Brasileira para o Progresso da Ciência. Goiânia-Go, 2011.

OLIVEIRA, E.A.S.; NINA-E-SILVA, C.H.; ALVARENGA, L.F. Influência da indução de dor sobre o comportamento exploratório de camundongos albinos (Mus musculus) no labirinto em cruz elevado. Revista da Universidade Vale do Rio Verde, 10(1), p.610-614, 2013.

PAWLAK, C.; KARRENBAUER, B.D.; SCHNEIDER, P.; HO, Y.J. The elevated plus-maze test: differential psychopharmacology of anxiety-related behavior. Emotion Review, 4(1), p.98-115, 2012. 
SILVA, L.L.; SORREGOTTI, T.; EBINA, A.H.; NUNES-DE-SOUZA, R.L. Avaliação da aversão condicionada por lugar provocada por estímulo nociceptivo em camundongos expostos a uma plataforma elevada. Anais do XXI Congresso de Iniciação Científica da UNESP. São José do Rio Preto-SP, 2009.

STOCCHE, R.W.; GARCIA, L.V.; KLAMT, J.G. Anestesia e Resposta Neuroendócrina e Humoral ao Estresse Cirúrgico. Revista Brasileira de Anestesiologia, 51(1), p.59-69.

ZHONG, X.L.; WEI, R.; ZHOU, P.; LUO, Y.W.; WANG, X.Q.; DUAN, J.; BI, F.F.; ZHANG, J.Y; LI, C.Q.; DAI, R.P.; LI, F. Activation of Anterior Cingulate Cortex Extracellular Signal-Regulated Kinase-1 and 2 (ERK1/2) Regulates Acetic Acid-Induced, Pain-Related Anxiety in Adult Female Mice. Acta Histochemica et Cytochemica, 45(4), p.219-225, 2012. 